\title{
Beneficent Persuasion: Techniques and Ethi- cal Guidelines to Improve Patients' Decisions
}

\author{
J. S. Swindell, $P b D^{1}$ \\ Amy L. McGuire, JD, PbD \\ Scott D. Halpern, MD, $P b D, M B E^{2,3}$ \\ ${ }^{1}$ Center for Medical Ethics and Health \\ Policy, Baylor College of Medicine, \\ Houston, Texas \\ ${ }^{2}$ Division of Pulmonary and Critical Care \\ Medicine; Center for Bioethics; Leonard \\ Davis Institute of Health Economics, \\ Philadelphia, Pennsylvania \\ ${ }^{3}$ Center for Clinical Epidemiology and \\ Biostatistics; University of Pennsylva- \\ nia School of Medicine, Philadelphia, \\ Pennsylvania
}

\begin{abstract}
Physicians frequently encounter patients who make decisions that contravene their long-term goals. Behavioral economists have shown that irrationalities and self-thwarting tendencies pervade human decision making, and they have identified a number of specific heuristics (rules of thumb) and biases that help explain why patients sometimes make such counterproductive decisions. In this essay, we use clinical examples to describe the many ways in which these heuristics and biases influence patients' decisions. We argue that physicians should develop their understanding of these potentially counterproductive decisional biases and, in many cases, use this knowledge to rebias their patients in ways that promote patients' health or other values. Using knowledge of decision-making psychology to persuade patients to engage in healthy behaviors or to make treatment decisions that foster their long-term goals is ethically justified by physicians' duties to promote their patients' interests and will often enhance, rather than limit, their patients' autonomy. We describe techniques that physicians may use to frame health decisions to patients in ways that are more likely to motivate patients to make choices that are less biased and more conducive to their long-term goals. Marketers have been using these methods for decades to get patients to engage in unhealthy behaviors; employers and policy makers are beginning to consider the use of similar approaches to influence healthy choices. It is time for clinicians also to make use of behavioral psychology in their interactions with patients.
\end{abstract}

Ann Fam Med 2010;8:260-264. doi:10.1370/afm.1118.

\section{INTRODUCTION}

$\mathrm{P}$ hysicians frequently encounter patients who make choices that contravene their long-term goals. Smoking, eating poorly, not exercising, failing to get regular mammography and colorectal screenings, and not vaccinating children are among the most obvious of these seemingly bad decisions. More subtly, but also quite commonly, patients make curious treatment decisions. An elderly patient with mild, asymptomatic coronary artery disease might request a percutaneous intervention despite evidence and his clinician's best judgment that medical therapy would provide a better risk-to-benefit ratio. A patient with surgically resectable lung cancer may opt to forego surgery because she believes it would spread the cancer. ${ }^{1}$

Behavioral economists have shown that self-thwarting tendencies pervade human decision making, and they have identified a number of specific operating heuristics and biases that help explain why patients sometimes make such counterproductive decisions. In this essay we describe the many ways in which these heuristics and biases influence patients' decisions and argue that often the most ethically appropriate response will be for physicians to use knowledge of these potentially destructive decisional biases to rebias their patients in ways that promote their health or other long-term goals. 


\section{Decision Biases and Heuristics}

Traditional models of medical decision making are based on rational choice, which assume that decision makers aim to maximize their utility and that decision makers' preferences are invariable regardless of how a choice is presented (eg, $60 \%$ chance of dying vs a $40 \%$ chance of living). Behavioral economists have shown otherwise, however. For example, people tend to overweigh their utilities for gains and underweigh their utilities for losses, to inaccurately project their utilities in a future time period, to reverse their preferences depending on how their options are framed, and to adopt a passive default position (thereby risking errors of omission) rather than actively make a choice (thereby risking a similar or often smaller error of commission). These biases and heuristics influence all decisions, including medical decisions. Table 1 illustrates a number of these biases and heuristics and provides examples of how they might play out in the clinical setting. ${ }^{3}$

\section{Ethical Justification for Beneficent Persuasion and Suggested Techniques}

During the past several decades, medicine has shifted away from a model in which physicians were largely charged with making decisions that they believed served their patients' best interests. Spurred by notorious examples of abuse ${ }^{4}$ and a growing appreciation for the importance of nonmedical values in decision making, this model came to be viewed as unnecessarily paternalistic. In its place has evolved a model of shared decision making in which clinicians serve to provide medical facts and occasionally recommendations, but patients make the ultimate decisions. ${ }^{5}$ This model is predicated on the assumption that patients are in the best position to decide their health care goals based on their personal values. The assumption is unassailable-who else could better tap into a patient's desires? But it also leads to a deceivingly simple conclusion that, given their unique knowledge of their values and goals, patients can consistently make choices that promote those values and goals. This latter premise may often prove incorrect, because the decisional biases and heuristics, introduced in Table 1, cast doubt on the ability of patients to access and act upon their own preferences. These biases and heuristics show that a patient's thinking, desires, and motivations are often highly dependent on and distorted by context. It may therefore be appropriate for physicians to try to rechannel these contextual influences in ways that assist people in achieving the commonly shared goal of long-term health (or, in cases where long-term health is not the only goal, then in ascertaining and achieving the patient's other goals). To illustrate these points, we will address a range of clinical situations and provide suggestions for when such rechanneling is appropriate and how to accomplish it.

To promote both the ethical principle of respect for autonomy and the principle of beneficence, physicians must first understand the nature of these heuristics and biases and then learn to recognize when they may be inappropriately influencing their patients' or their own decisions. In cases where there is one

Table 1. Biases and Heuristics That May Impede Optimal Patient Decisions

\begin{tabular}{|c|c|}
\hline Cognitive or Affective Bias/Heuristic & Clinical Example \\
\hline $\begin{array}{l}\text { Availability heuristic: being influenced by what is most read- } \\
\text { ily available in memory-recent, rare, and vivid events } \\
\text { hold exceptional sway }\end{array}$ & $\begin{array}{l}\text { A parent refuses to vaccinate her child after she sees an isolated media report } \\
\text { of a child who developed autism after being vaccinated }\end{array}$ \\
\hline $\begin{array}{l}\text { Feeling vulnerable effect: being influenced by affective risk } \\
\text { perceptions instead of cognitive ones }\end{array}$ & $\begin{array}{l}\text { A smoker correctly estimates her probability of developing lung cancer to be } \\
\text { high but reports that she nevertheless does not believe she is susceptible, } \\
\text { and hence does not quit smoking }\end{array}$ \\
\hline $\begin{array}{l}\text { Focusing effect/side-effect aversion: being influenced sub- } \\
\text { stantially more by short-term concerns and interests than } \\
\text { by long-term goals }\end{array}$ & $\begin{array}{l}\text { A patient chooses to forgo recommended colorectal screening because of its } \\
\text { inconveniences despite wishing to live as long as possible }\end{array}$ \\
\hline $\begin{array}{l}\text { Gambler's fallacy: being influenced by unrelated past } \\
\text { occurrences }\end{array}$ & $\begin{array}{l}\text { A patient thinks that because she has developed so many incident health prob- } \\
\text { lems in the past year, she is unlikely to also develop breast cancer because } \\
\text { she is "due for a break." She thus skips her mammography }\end{array}$ \\
\hline $\begin{array}{l}\text { Impact bias/affective forecasting error: being influenced } \\
\text { by inaccurate projections of future states }\end{array}$ & $\begin{array}{l}\text { A patient delays getting a colostomy because he predicts that he will be } \\
\text { extremely unhappy, even though studies show that those who have under- } \\
\text { gone the procedure rate their quality of life as being the same as before, } \\
\text { and report wishing they had done it sooner }\end{array}$ \\
\hline $\begin{array}{l}\text { Omission bias: preferring inaction to avoid harm even though } \\
\text { it may cause a similar or greater harm than the action }\end{array}$ & $\begin{array}{l}\text { A patient with atrial fibrillation refuses to take warfarin because she is con- } \\
\text { cerned about causing a hemorrhagic stroke, despite the greater risk of isch- } \\
\text { emic stroke if she does not take the warfarin }\end{array}$ \\
\hline $\begin{array}{l}\text { Escalation/cascade effect: preferring the path already taken } \\
\text { in favor of other paths that might clearly produce better } \\
\text { results but require a change of habit or routine }\end{array}$ & $\begin{array}{l}\text { Patients continue to make choices that produce negative health effects (eg, not } \\
\text { exercising, smoking) because they have been doing it for so long already }\end{array}$ \\
\hline $\begin{array}{l}\text { Sunk cost bias: continuing with a plan of action, even when } \\
\text { it is clear that there is no payoff, just because resources } \\
\text { have already been invested into that plan }\end{array}$ & $\begin{array}{l}\text { A patient with osteoarthritis continues taking a drug just because she already } \\
\text { purchased a large supply even though after many months of taking it she } \\
\text { notices no difference in her knee pain }\end{array}$ \\
\hline
\end{tabular}


treatment or prevention approach that best helps the patient achieve her long-term goals, physicians should act as beneficent persuaders-using knowledge of decisional psychology to influence the patient to choose that approach (Table 2). For example, if physicians have good reason to believe that patients are falling prey to the availability heuristic (Table 1) and thus making decisions that do not promote their goals, then the physician might counteract this tendency by making other examples more vivid. Imagine a 30 yearold pregnant patient, herself a physician, who after much research and contemplation has elected to forgo amniocentesis because of its attendant risks. This patient changes her mind, however, after seeing one vivid example of an infant with a chromosomal abnormality in the hospital waiting room. ${ }^{16}$ In this case, the clinician might direct the patient's attention to the many other children in the waiting room or elsewhere who were born perfectly healthy without amniocentesis. Such an intervention is ethically justified because the best available evidence suggests this woman is not at sufficiently high risk for an abnormal pregnancy to accept the risks of amniocentesis to achieve her goals for health for herself and her fetus. Such explicit efforts to rebias patients may supplement clinicians'

\begin{tabular}{|c|c|}
\hline $\begin{array}{l}\text { Persuasive } \\
\text { Techniques }\end{array}$ & Examples of Beneficent Persuasion \\
\hline \multirow[t]{2}{*}{ Vivid depictions 6} & $\begin{array}{l}\text { When discussing risks of continuing to smoke with patients, show them } \\
\text { ventilated COPD patients in a medical ICU or a video of a patient with } \\
\text { advanced lung cancer }\end{array}$ \\
\hline & $\begin{array}{l}\text { To offset parents' concerns about the risks of vaccination, deploy your } \\
\text { clinic's waiting room television to show videos of children who have suf- } \\
\text { fered from not being vaccinated }\end{array}$ \\
\hline Defaults $^{7}$ & $\begin{array}{l}\text { Make it policy to schedule evidence-based screenings (eg, colorectal, mam- } \\
\text { mography, HIV testing) for your patients automatically, framing these as } \\
\text { the default option similarly to how you might frame cholesterol screening }\end{array}$ \\
\hline \multirow[t]{2}{*}{ Regret $^{8}$} & $\begin{array}{l}\text { Encourage your patients to think about the regret they may feel if they do } \\
\text { not follow recommendations regarding cancer screening and an early } \\
\text { cancer diagnosis is subsequently missed }\end{array}$ \\
\hline & $\begin{array}{l}\text { Encourage your patients to anticipate the regret they may feel (toward } \\
\text { themselves, toward their children) if they continue to smoke and then } \\
\text { develop lung cancer }\end{array}$ \\
\hline \multirow[t]{4}{*}{ Framing ${ }^{9-13}$} & $\begin{array}{l}\text { When discussing mammography with patients for whom it is indicated, } \\
\text { frame the associated risk reduction in mortality from breast cancer in } \\
\text { terms of relative rather than absolute risks }\end{array}$ \\
\hline & $\begin{array}{l}\text { When counseling healthy patients with no risk factors who want a full-body } \\
\text { CT scan "just to be sure," explain risk reduction of CT scan in absolute } \\
\text { terms rather than relative terms, or focus their attention on the risks of } \\
\text { the CT scan, including the risks of receiving false-positive results }\end{array}$ \\
\hline & List benefits first, side-effects next, and then repeat benefits again \\
\hline & $\begin{array}{l}\text { Frame results of self-neglect in terms of losses instead of discussing the } \\
\text { gains of self-care. }\end{array}$ \\
\hline Refocusing ${ }^{14,15}$ & $\begin{array}{l}\text { Encourage newly disabled patients to think about how well they adapted to } \\
\text { new challenges in the past and all the capacities for future happiness that } \\
\text { they have retained despite their injury. }\end{array}$ \\
\hline
\end{tabular}

other tools for engaging productively with patients, such as using empathy, respect, negotiation, and other good communication skills.

We expect that in cases where there is only one clear medically beneficial choice, for example, taking medication when diagnosed with hypertension and high cholesterol, there will be few objections to clinicians' using the suggested persuasive rebiasing techniques. More controversial will be cases on the other end of the spectrum, where the best decision for a specific patient is less certain, such as when there is clinical equipoise regarding a treatment's effectiveness or when the decision to be made requires balancing several different sets of values and goals, such as decisions about termination of a pregnancy. In such cases, the clinician is not ethically justified in attempting to persuade the patient in one direction or another. Instead, clinicians ought to make the patient aware of how some of these decisional biases may be influencing their decision making so as to enhance autonomous choice. For example, a dialysis patient who recently had a leg amputation and was also left by her romantic partner may fall prey to the impact bias (Table 1) and choose to forego dialysis because she thinks that she will never get over this loss. ${ }^{14}$ Although it may not be clear what choice is in this patient's best interests (or what her long-term goals are), the clinician should inform her about how the impact bias works (that people tend to overestimate how long and intense their pain will be when something bad happens to them) and make her aware that it may be influencing her decision.

Clear-cut cases may be rare, and in most cases the best clinical decision will be ambiguous. For example, a patient with advanced pulmonary arterial hypertension who is in right-sided heart failure may choose to try recently approved oral therapies despite her clinician's belief that, given the advanced nature of the disease, a continuous intravenous infusion of epoprostenol gives her the best chance for meaningful survival. Although the clinician may understand the patient's reluctance to have an indwelling catheter to accommodate the infusion, such preferences may be unduly influenced by 
the focusing effect and impact bias (Table 1). In this case, the patient may be vulnerable to decision-making biases, but the patient's best interests are not entirely certain (ie, it is conceivable that some patients may truly prefer avoiding the inconveniences or risks of an indwelling catheter, even if it substantially increases their risk for death from disease progression). In cases entailing such trade-offs, we recommend that the clinician first attempt to understand the patient's goals and then make the patient aware of how biases (such as focusing effect/side-effect aversion, Table 1) may be negatively affecting her decision making by thwarting those goals. If the patient persists in choosing a treatment approach that the clinician believes is deleterious to her welfare or long-term goals, some clinicians may choose to persuasively rebias the patient by framing the likely consequences starkly (perhaps pictorially). Physicians confronting such ambiguous cases should also consider negotiating alternatives with patients. For example, in caring for this patient with pulmonary arterial hypertension, the clinician might work with the patient to negotiate a trial period of infusion. By exploring and addressing the various concerns that the patient has about the burdens and side effects of an indwelling catheter, this negotiation may also help to de-emphasize counterproductive influences on decisions.

\section{Concerns With Beneficent Persuasion}

Some may worry that these persuasive rebiasing techniques could too easily be misused by clinicians to inappropriately bias patients and paternalistically coerce them into making decisions that are inconsistent with their own values and beliefs. We emphasize that clinicians should not use knowledge of decisional psychology to serve their own interests-whether personal, financial, religious, or otherwise. This emphasis inevitably requires some trust that clinicians will prioritize their patients' interests, but this trust is no different from the trust we must always have in physicians to behave professionally and exercise their fiduciary obligations to their patients. Persuasion using methods garnered from decisional psychology is justified only to the extent that it is in the best interests of the patient. Moreover, a patient's best interests and goals are determined by the patient, not the physician. The physician is merely ascertaining them and rebiasing the patient toward them.

In many cases, the patient's goals will primarily focus on longevity and freedom from symptoms, but other goals (eg, maintaining one's physical appearance or financial security) should also be explored. Of course, physicians also need to be aware of how these same decisional biases and heuristics are influencing their own decisions. Finally, some may also be concerned that any sort of persuasion-even beneficent-is unethical. This view is untenable, because some persuasion, however subtle, is inescapable in the sense that clinicians must always frame things one way or the other. For example, physicians must choose whether to offer lumpectomy or mastectomy first for their patients with breast cancer. Given the potentially differing impacts of options based on the priority of primacy vs recency, even such seemingly trivial decisions may be persuasive. Second, and most important, the persuasion is often more than just beneficent ${ }_{i}$ it is often a way to bring the patient to a well-rounded view of the decision at hand and the issues at stake. Abandoning patients in the decision-making process, leaving them to make their own (potentially bad) decisions, merely pays lip service to the promotion of autonomy. ${ }^{17,18}$

Using knowledge of decision-making psychology to rebias patients to persuade them to engage in healthy behaviors or make good treatment decisions is ethically justified when the patients' biases or heuristics are distorting their decisions in harmful and potentially correctable ways. Using methods described in this essay, clinicians may frame health decisions to patients in ways that are more likely to motivate patients to make better choices, ie, less biased and more consistent with their long-term goals. Marketers have used framing and other methods garnered from behavioral psychology and behavioral economics for decades to get people to make unhealthy choices. Employers and policy makers are beginning to consider the use of behavioral psychology to influence healthy choices. ${ }^{19,20}$ It is time for clinicians to also make use of behavioral psychology in their personal interactions with patients. ${ }^{21}$

To read or post commentaries in response to this article, see it online at http://www.annfammed.org/cgi/content/full/8/3/260.

Key words: Decision making; professional autonomy; informed consent; ethics; persuasive communication

Submitted May 20, 2009; submitted, revised, September 17, 2009; accepted November 2, 2009.

\section{References}

1. Margolis ML, Christie JD, Silvestri GA, Kaiser L, Santiago S, Hansen-Flaschen J. Racial differences pertaining to a belief about lung cancer surgery: results of a multicenter survey. Ann Intern Med. 2003;139(7):558-563.

2. Smith DM, Sherriff RL, Damschroder L, Loewenstein G, Ubel PA Misremembering colostomies? Former patients give lower utility ratings than do current patients. Health Psychol. 2006;25(6):688-695.

3. Klein WM, Stefanek ME. Cancer risk elicitation and communication: lessons from the psychology of risk perception. CA Cancer J Clin. 2007;57(3):147-167.

4. Burten K. Dax's case. [Documentary film]. Produced by Unicorn Media Inc, for Concern for Dying. USA; 1985. 
5. Savulescu J. Rational non-interventional paternalism: why doctors ought to make judgments of what is best for their patients. J Med Ethics. 1995;21(6):327-331.

6. Volandes AE, Paasche-Orlow MK, Barry MJ, et al. Video decision support tool for advance care planning in dementia: randomised controlled trial. BMJ. 2009;338:b2159.

7. Halpern SD, Ubel PA, Asch DA. Harnessing the power of default options to improve health care. N Engl J Med. 2007;357(13): 1340-1344.

8. Richard R, van der Pligt J, de Vries N. Anticipated regret and time perspective: changing sexual risk-taking behavior. J Behav Decis Making. 1996;9(3):185-199.

9. Cranney M, Walley T. Same information, different decisions: the influence of evidence on the management of hypertension in the elderly. Br J Gen Pract. 1996;46(412):661-663.

10. Carling C, Kristoffersen D, Montori V, et al. The effect of alternative summary statistics for communicating risk reduction on decisions about taking statins: a randomized trial. PLoS Med. 2009;6(8): e31000140.

11. Lipkus IM, Klein WMP. Effects of communicating social comparison information on risk perceptions for colorectal cancer. J Health Commun. 2006;11(4):391-407.

12. Banks SM, Salovey P, Greener S, et al. The effects of message framing on mammography utilization. Health Psychol. 1995;14(2):178-184.
13. Waters EA, Weinstein ND, Colditz GA, Emmons KM. Reducing aversion to side effects in preventive medical treatment decisions. J Exp Psychol Appl. 2007;13(1):11-21.

14. Halpern J. From Detached Concern to Empathy: Humanizing Medical Practice. 1st ed. London: Oxford University Press; 2001.

15. Ubel $P$, Loewenstein $G$, Jepson $C$. Disability and sunshine: can hedonic predictions be improved by drawing attention to focusing illusions or emotional adaptation? J Exp Psychol Appl. 2005;11(2):111-123.

16. Ubel P. Free Market Madness: Why Human Nature Is At Odds With Economics-And Why It Matters. 1st ed. Cambidge, MA: Harvard Business Press; 2009

17. Brock DW, Wartman SA. When competent patients make irrational choices. N Engl J Med. 1990;322(22):1595-1599.

18. Katz J. The Silent World of Doctor and Patient. 1st ed. Baltimore, MD: The Johns Hopkins University Press; 2002.

19. Okie S. The employer as health coach. N Engl J Med. 2007;357 (15):1465-1469.

20. Loewenstein G, Brennan T, Volpp KG. Asymmetric paternalism to improve health behaviors. JAMA. 2007;298(20):2415-2417.

21. Ubel PA. "What should I do, doc?": Some psychologic benefits of physician recommendations. Arch Intern Med. 2002;162(9):977-980. 